\title{
Изучение взаимодействия терпено-индольных алкалоидов с компонентами крови методом гель-фильтрации
}

\author{
Халахакун А.Д., Тринеева О.В., Сливкин А.И. \\ ФГБОУ ВО «Воронежский государственный университет», Воронеж
}

Поступила в редакцию 21.12.2017 г.

DOI: https://doi.org/10.17308/sorpchrom.2018.18/497

Экспериментальными исследованиями in vitro установлено, что терпено-индольные алкалоиды обладают высокой способностью связываться с компонентами плазмы и форменными элементами крови. С компонентами плазмы связывание осуществляется на 52.67\% для винкристина и на 53.04\% для винбластина от общего связывающегося количества изучаемых препаратов. В эксперименте показано, что взаимодействие винкристина с форменными элементами крови (эритроцитами) составляет $46.91 \%$, а винбластина - $46.23 \%$ от вводимой дозы. В соответствии с полученными данными, можно определить оптимальные условия для инкапсулирования исследуемых алкалоидов в эритроцитах для создания клеточных носителей и осуществления направленного транспорта данных лекарственных веществ в организме.

Ключевые слова: винкристин, винбластин, направленный транспорт лекарственных веществ, связывание с компонентами плазмы и форменными элементами крови.

\section{Study of interaction of terpeno-indole alkaloids with blood components by the gel filtration method}

\author{
Halahakoon A. J., Trineeva O.V., Slivkin A.I. \\ Voronezh State University, Voronezh
}

The problems of directional transport of drugs in the body, which make it possible to maximize the effectiveness of therapy and reduce systemic toxic side reactions, are becoming increasingly important. In the literature, there is evidence of the possibility of using cellular carriers as delivery systems for various drugs to pathologically altered organs and target cells. In connection with this, it is important to study the possibility of using cellular carriers to load highly toxic antitumoral alkaloids of the indole group that are part of the standards for the treatment of certain oncological diseases - vincristine and vinblastine, in order to reduce side effects, improve the effectiveness of the drug, and tolerate chemotherapy. To solve this problem, it is necessary to study the pharmacokinetic characteristics of the interaction of these drugs with plasma and cellular elements of blood to develop a rational technique for encapsulating these drugs in erythrocytes.

To obtain the erythrocyte cell form of the studied substances, a modified method of hypoosmotic lysis was used. Isolation of alkaloids from the biological material was carried out by the gel filtration method. It has been established that the preparations of terpene-indole alkaloids have a high ability to bind to plasma components and shaped elements of blood. With components of the plasma binding is carried out for vincristine at $52.67 \%$, and for vinblastine $-53.04 \%$ of the total binding amount of preparations of alkaloids. In the experiment, it was found that the interaction of vincristine with the shaped elements of blood (erythrocytes) is $46.91 \%$, and vinblastine $-46.23 \%$ of the administered dose. In accordance with the obtained experimental data, it is possible to determine the optimal conditions for encapsulating these preparations in erythrocytes to create cellular carriers and to carry out directed transport of these drugs in the body. 
Keywords: vincristine, vinblastine, directed transport of medicinal substances, binding with plasma components and shaped elements of blood.

\section{Введение}

Проблемы направленного транспорта лекарственных веществ в организме, позволяющие максимально повысить эффективность терапии и снизить системные токсические побочные реакции, приобретают все большую актуальность. В литературе имеются сведения о возможности использования клеточных носителей (КН) в качестве систем доставки различных лекарственных средств к патологически измененным органам и клеткам-мишеням. В научных публикациях пока отсутствуют сведения о применении КН для винкристина (VCR) и винбластина (VBL) - высокотоксичных противоопухолевых алкалоидов группы индола, входящих в стандарты лечения некоторых онкологических заболеваний. В связи с этим актуальным является исследование возможности применения КН для загрузки VCR и VBL с целью уменьшения побочных явлений, улучшения эффективности препарата и переносимости химиотерапии. Для решения данной задачи необходимо изучить фармакокинетические характеристики взаимодействия данных препаратов с плазмой и клеточными элементами крови для разработки рациональной методики инкапсулирования VCR и VBL в эритроцитах.

Цель работы - изучение взаимодействия терпено-индольных алкалоидов (ТИА) - винкристина и винбластина сульфатов с компонентами плазмы и форменными элементами крови для создания КН и осуществления направленного транспорта данных лекарственных веществ в организме.

Существуют научные исследования, свидетельствующие, что после внутривенного введения VCR и VBL тесно связываются с белками плазмы, в том числе $\alpha 1-$ кислым гликопротеином, альбумином, липопротеином, а также с форменными элементами крови (тромбоцитами, лимфоцитами, эритроцитами, моноцитами и т.д.) [1]. В данном эксперименте рассматривалось взаимодействие VCR и VBL с плазмой и форменными элементными крови in vitro.

\section{Эксперимент}

Объектами исследований являлись винкристина сульфат («ВинкристинТева», «Teva Pharmaceutical Industries Ltd». - Израиль; «VERO-винкристин», «ЛЭНС-ФАРМ» - Россия; «Винкристин-Рихтер», «Gedeon Richter Ltd». - Венгрия) и

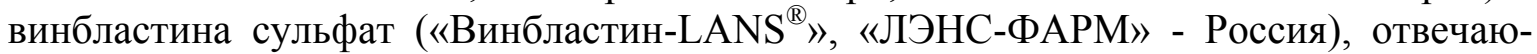
щие требованиям действующей нормативной документации в России.

Для получения эритроцитарной клеточной формы изучаемых веществ использовали модифицированный метод гипоосмотического лизиса. Для изучения взаимодействия VCR и VBL с плазмой и форменными элементами крови, приготовлены 3 типа модельных образцов: образец А - (кровь + препараты); образец Б (плазма + препараты); образец В - (эритроциты + препараты).

В эксперименте использовали кровь, взятую из хвостовой вены белых беспородных крыс с соблюдением правил гуманного обращения с животными. В качестве антикоагулянта использовали гепарин в соотношении $0.1 \mathrm{~cm}^{3}$ к $1.5 \mathrm{~cm}^{3}$ крови с активностью $5000 \mathrm{ED}$. Полученную кровь хранили в холодильнике при $+4^{\circ} \mathrm{C}$ до времени использования.

Oбразец A: к $1.0 \mathrm{~cm}^{3}$ полученной крови добавили 1.0 мг VCR и инкубировали 20 мин при $37^{\circ} \mathrm{C}$. После инкубации проводился полный гемолиз эритроцитов, путём 
добавления в кровь пятикратного количества воды и полученный гемолизат центрифугировали при 2000 об/мин в течение 20 мин при комнатной температуре $\left(20^{\circ} \mathrm{C}\right)$. После центрифугирования супернатант аккуратно отбирали и переносили в центрифужную пробирку на $15 \mathrm{~cm}^{3}$ и разбавляли водой очищенной до $6.0 \mathrm{~cm}^{3}$. Полученный гемолизат нагревали при $80^{\circ} \mathrm{C}-20$ мин на водяной бане, затем охлаждали до комнатной температуры, фильтровали через бумажный фильтр. Полученный фильтрат еще раз пропускали через фильтр с размером пор 0.45 мкм («Millipore»). Аналогичная процедура проводилась так же для VBL. Полученный образец вводили в верхний слой хроматографической колонки.

Образец Б: для получения плазмы $10 \mathrm{~cm}^{3}$ гепарированной крови помещали в центрифужную пробирку на $15 \mathrm{~cm}^{3}$ и центрифугировали при 4000 об/мин в течение 10 мин при комнатной температуре. Разделенные фракции плазмы аккуратно собирали силиконовыми пипетками, не нарушая лейкоцитарную пленку и перемещали в чистую пробирку на $15 \mathrm{~cm}^{3}$. Изолированную фракцию плазмы еще раз центрифугировали при 8000 об/мин 15 мин для удаления отставших клеток. Содержание форменных элементов в плазме контролировали под микроскопом (Levenhuk 870T, тринокуляр (КНР для Levenhuk, Inc. - США) при помощи сетки Горяева, для чего пробы разводили в 200 раз физиологическим раствором натрия хлорида. Изолированные фракции плазмы хранили при $4^{\circ} \mathrm{C}$ до момента использования. Отделенную плазму фильтровали через фильтр с размером пор 0.45 мкм. $0.55 \mathrm{~cm}^{3}$ полученной плазмы переносили в чистую пробирку и добавляли 1.0 мг VCR или VBL. Содержимое пробирки инкубировали в течении 20 мин при $37^{\circ} \mathrm{C}$. Полученный образец разбавляли водой дистиллированной до $2.0 \mathrm{~cm}^{3}$ и вводили в верхний слой хроматографической колонки.

Образец В: гепарированную кровь разводили до 2-х кратного объёма добавлением раствора $0.01 \mathrm{M} \mathrm{Na-фосфатного} \mathrm{буферного} \mathrm{раствора.} \mathrm{В} \mathrm{центрифужную} \mathrm{про-}$ бирку на $15 \mathrm{~cm}^{3}$ вносили на $10 \mathrm{~cm}^{3}$ раствора фиколла $\left(1.077\right.$ г/ $\left.\mathrm{cm}^{3}\right)$ и аккуратно $3 \mathrm{~cm}^{3}$ разведенной крови сверху раствора фиколла. Пробирку центрифугировали при 2000 об/мин в течение 40 мин в комнатной температуре. После центрифугирования форменные элементы фракционировали в соответствии с их плотностью: верхний слой - плазма крови, затем слой мононуклеарных клеток, далее слой фиколла, следующие фракции эритроциты и гранулоциты. Фракцию плазмы аккуратно собирали с помощью пипетки, мононуклеарный клеточный слой собирали чистой пипеткой и переносили в чистую пробирку. Раствор фиколла собирается аккуратно, не затрагивая фракции эритроцитов на дне пробирки. Фракцию, гранулированную эритроцитами, промывали 2-х кратным объёмом 0.01 M Na-фосфатного буферного раствора, и центрифугировали при 3000 об/мин 10 мин при комнатной температуре. После окончания центрифугирования супернатант аккуратно отбрасывали. Процедуру повторили 2 раза. После последнего промывания эритроциты суспендировали в изотоническом растворе $\mathrm{NaCl}$, содержащем $3 \%$ декстрана, и хранили в холодильнике при $+4^{\circ} \mathrm{C}$ до времени использования. Присутствие других форменных элементов в суспензии эритроцитов контролировали микроскопированием, как указано выше. $0.45 \mathrm{~cm}^{3}$ клеточной массы переливали в чистую пробирку и добавляли 1.0 мг VCR или VBL, инкубировали в течение 20 мин при $37^{\circ} \mathrm{C}$. После инкубации проводился полный гемолиз эритроцитов путём добавления в кровь пятикратного количества воды и полученный гемолизат центрифугировался при 2000 об/мин - 20 мин при комнатной температуре. После центрифугирования, супернатант аккуратно отбирали, фильтровали через фильтр с диаметром пор 0.45 мкм, переносили в пробирку объемом $10 \mathrm{~cm}^{3}$, разбавляя водой дистиллированной до $6.0 \mathrm{~cm}^{3}$ и вводили в верхний слой хроматографической колонки. 
Для колоночной хроматографии использовалась стеклянная трубка диаметром 10 мм и длиной 25 см. Сухой Сефадекс G-25 массой 5.0 г помещали в коническую колбу вместимостью $100 \mathrm{~cm}^{3}$, добавляли $50 \mathrm{~cm}^{3}$ воды дистиллированной, нагревали на водяной бане в течение 1 ч, затем охлаждали до комнатной температуры. Пробку из стекловаты встраивали в колонну с помощью стеклянной палочки. Охлажденную суспензию геля тщательно перемешивали и выливали в колонку с помощью стеклянной палочки. Гель в колонке уплотняли, после чего длина которой соответствовала 10 и $5.1 \mathrm{~cm}$, а общий объём колонки $\left(\mathrm{V}_{0}\right)$ составлял 7.85 и $4 \mathrm{~cm}^{3}$ соответственно.

После подготовки колонки для гель-фильтрации [2-13], при помощи шприца модельные образцы аккуратно вводили в верхний слой колонки и элюировали с использованием воды очищенной. Скорость элюента составляла $8-15 \mathrm{~cm}^{3} /$ ч для разных колонок (таблица 1). Собирали фракции по $2.0 \mathrm{~cm}^{3}$ (рис. 1).

Таблица 1. Характеристики хроматографического элюирования ТИА препаратов*

\begin{tabular}{|c|c|c|c|c|}
\hline \multirow{2}{*}{ № колонки } & \multirow{2}{*}{ Элюент } & \multicolumn{2}{|c|}{ Vo, мл } & \multirow{2}{*}{ Скорость элюента, $\mathrm{cm}^{3}$ /ч } \\
\cline { 3 - 4 } & Вода очищенная & 54 & 52 & 10 \\
\hline I & $0.1 \mathrm{M} \mathrm{HCl}$ & 58 & 50 & 12 \\
\hline II & $0.1 \mathrm{M} \mathrm{NaOH}$ & 46 & 48 & 8 \\
\hline III & $\begin{array}{c}0,01 \mathrm{M} \mathrm{Na-Фосфатный} \\
\text { буферный раствор }\end{array}$ & 50 & 56 & 10 \\
\hline
\end{tabular}

*Длина слоя геля $=10$ см; тип геля - Сефадекс G-25

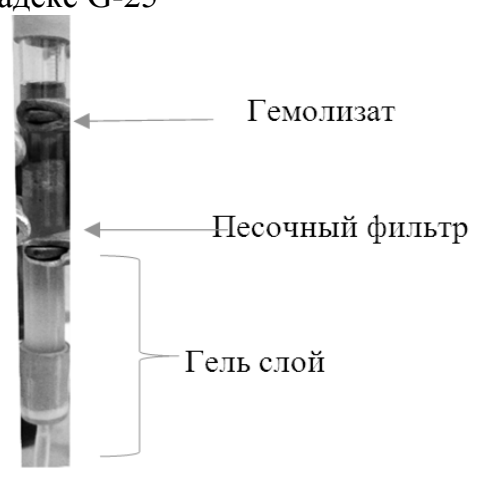

Рис. 1. Колонка с Сефадексом G-25 для гель-фильтрации для выделения ТИА препаратов из биологического материала (гемолизат крови)

Оптическую плотность каждой полученной фракции измеряли при помощи спектрофотометра Hitachi Ratio Beam Spectrophotometer U-1900 (Япония). Количественное содержание препаратов рассчитывали в соответствии с ранее разработанной и валидированной по ОФС.1.1.0012.15 «Валидация аналитических методик» ГФ ХІІІ спектрофотометрической методикой, основанной на измерении светопоглощения в максимумах при 295 нм для VCR и 268 нм для VBL в воде дистиллированной.

\section{Обсуждение результатов}

Элюентные хроматограммы представлены на рис. 2-4. Результаты эксперимента приведены в таблицах 2-6. Полученные данные демонстрируют эффективное отделение VCR и VBL от сопутствующих веществ крови и плазмы в хроматографических колонках. Высота надосадочного слоя влияет на разрешение и время, необходимое для элюирования. На рис. 2 видно, что разделение препаратов происходит эффективно и с хорошим разрешением при использовании колонки I (таблица 1). 

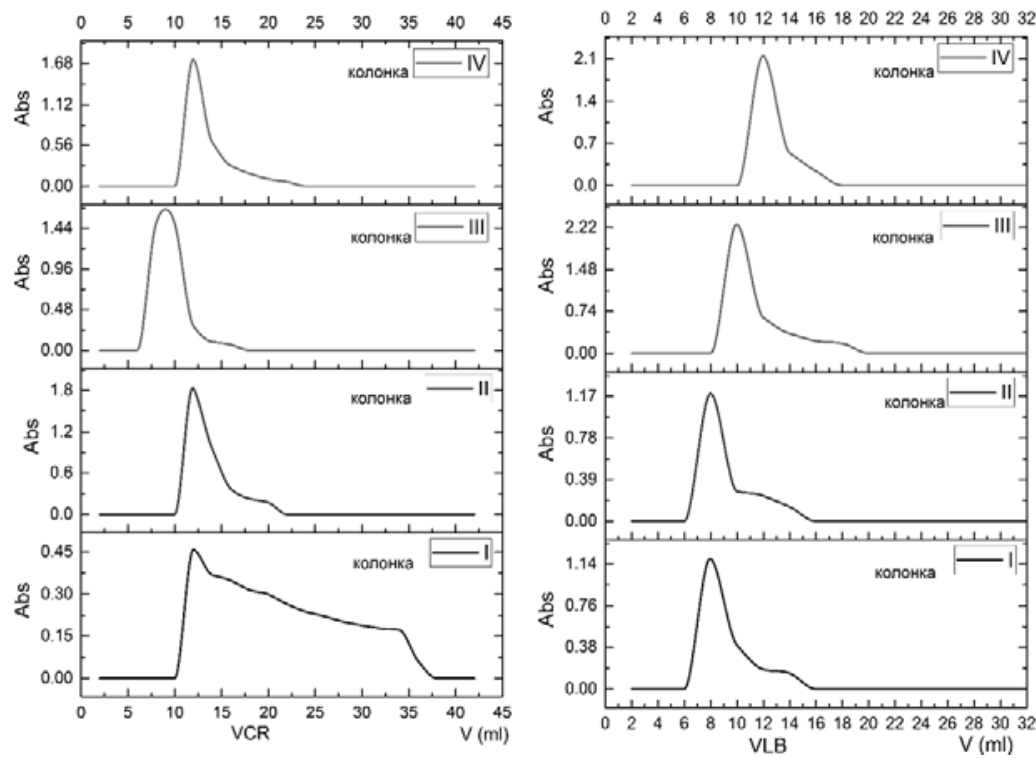

Рис. 2. Хроматограммы VCR и VBL в собранных фракциях из гемолизата крови
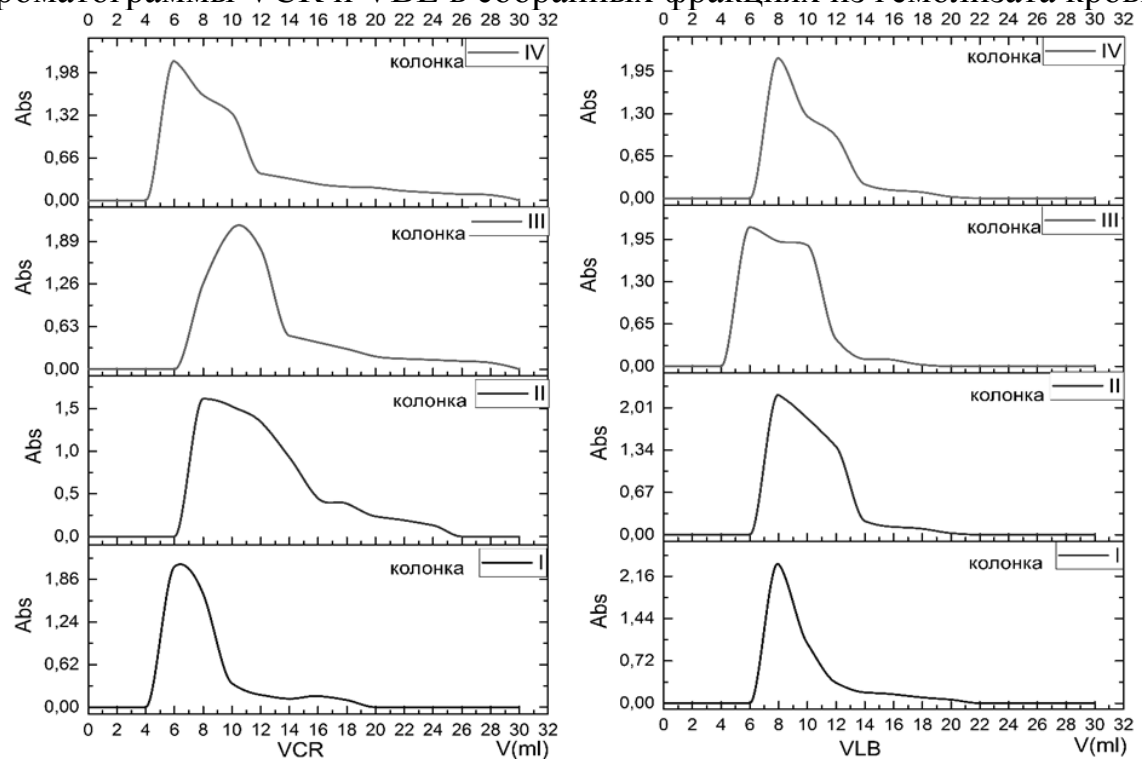

Рис. 3. Хроматограммы VCR и VBL собранных фракций из плазмы крови
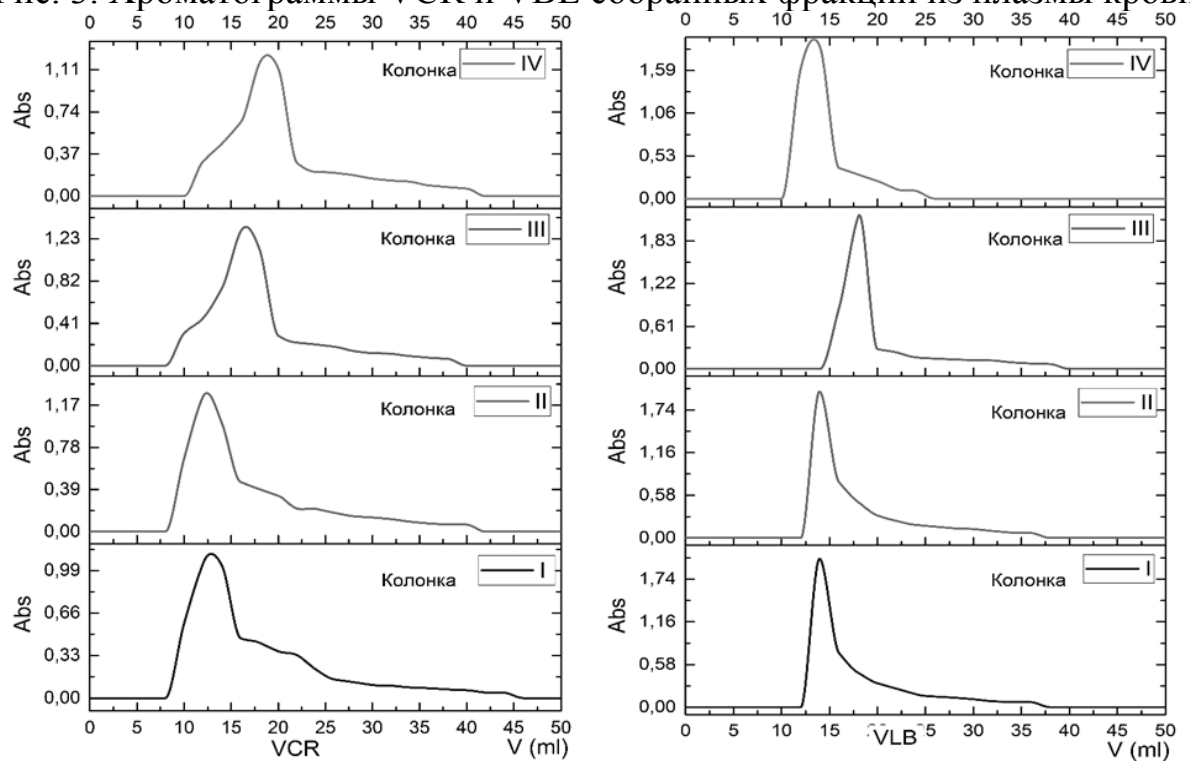

Рис. 4. Хроматограммы VCR и VBL собранных фракций из форменных элементов крови 
Таблица 2. Результаты количественного определения свободных ТИА в гемолизате крови

\begin{tabular}{|c|c|c|c|c|c|c|}
\hline \multirow[b]{2}{*}{$\begin{array}{l}\text { № ко- } \\
\text { лонки }\end{array}$} & \multirow[b]{2}{*}{$\begin{array}{c}\text { Длина } \\
\text { колонки, } \\
\text { см }\end{array}$} & \multirow{2}{*}{$\begin{array}{l}\text { Введено } \\
\text { ТИА } \\
\text { в образец, } \\
\text { мкг } \\
\end{array}$} & \multicolumn{3}{|c|}{ Найдено } & \multirow{2}{*}{$\begin{array}{c}\text { Уравнение прямой, ис- } \\
\text { пользованной для } \\
\text { количественного опре- } \\
\text { деления ТИА }\end{array}$} \\
\hline & & & МКГ & $\begin{array}{l}\mathrm{m}_{\mathrm{cp} .} \\
\text { (мКг) }\end{array}$ & $\begin{array}{l}\mathrm{m}_{\mathrm{cp}} \\
\% *\end{array}$ & \\
\hline \multicolumn{7}{|c|}{ VCR } \\
\hline I & 10 & 1000 & 341.42 & 25050 & & \multirow{4}{*}{$y=0.0195 x+0.0112$} \\
\hline II & 10 & 1000 & 375.74 & \multirow{3}{*}{352.74} & 35.86 & \\
\hline III & 5.1 & 1000 & 346.18 & & \multirow{2}{*}{35.27} & \\
\hline IV & 5.1 & 1000 & 359.29 & & & \\
\hline \multicolumn{7}{|c|}{ VBL } \\
\hline I & 5.1 & 500 & 216.56 & 21540 & & \multirow{4}{*}{$y=0.0192 x+0.0115$} \\
\hline II & 5.1 & 500 & 214.42 & \multirow{3}{*}{433.60} & 43.10 & \\
\hline III & 10 & 1000 & 444.29 & & \multirow{2}{*}{43.36} & \\
\hline IV & 10 & 1000 & 422.92 & & & \\
\hline
\end{tabular}

*SD - VCR $( \pm 1.537 \%)$, VBL $( \pm 0.902 \%)$

Таблица 3. Результаты количественного определения VCR и VBL в плазме крови

\begin{tabular}{|c|c|c|c|c|c|c|}
\hline \multirow{2}{*}{ № колонки } & \multicolumn{3}{|c|}{ Найдено } & \multicolumn{3}{|c|}{ Связанно } \\
\hline & МКГ & $\mathrm{R}, \%$ & $\mathrm{R}_{\mathrm{cp}}, \%$ & МКГ & $\mathrm{R}, \%$ & $\mathrm{R}_{\mathrm{cp}}, \% *$ \\
\hline \multicolumn{7}{|c|}{ VCR } \\
\hline I & 661.53 & 66.15 & \multirow{4}{*}{66.06} & 338.48 & 33.85 & \multirow{4}{*}{33.94} \\
\hline II & 659.57 & 65.96 & & 340.43 & 34.04 & \\
\hline III & 660.43 & 66.04 & & 339.57 & 33.96 & \\
\hline IV & 661.06 & 66.11 & & 338.94 & 33.89 & \\
\hline \multicolumn{7}{|c|}{ VBL } \\
\hline I & 699.42 & 69.94 & \multirow{4}{*}{69.89} & 300.58 & 30.06 & \multirow{4}{*}{30.25} \\
\hline II & 698.48 & 69.85 & & 301.52 & 30.15 & \\
\hline III & 699.66 & 69.97 & & 300.34 & 30.03 & \\
\hline IV & 697.97 & 69.80 & & 302.03 & 30.20 & \\
\hline
\end{tabular}

*SD - VCR $( \pm 0.846 \%)$, VBL $( \pm 0.791 \%)$

Таблица 4. Результаты количественного определения свободных и связанных VCR и VBL в крови

\begin{tabular}{|c|c|c|c|c|c|c|c|c|c|}
\hline \multirow{4}{*}{$\begin{array}{c}\text { Длина } \\
\text { колон- } \\
\text { ки, } \\
\text { см }\end{array}$} & \multirow{4}{*}{ тиА } & \multirow{4}{*}{$\begin{array}{c}\text { Вве- } \\
\text { дено в } \\
\text { образец, } \\
\text { мкг }\end{array}$} & \multicolumn{2}{|c|}{ Найдено } & \multicolumn{5}{|c|}{ Связанно } \\
\hline & & & \multirow{3}{*}{$\begin{array}{l}\text { в гемо- } \\
\text { лизате } \\
\left(\mathrm{m}_{\mathrm{cp}}\right), \text { мкг }\end{array}$} & \multirow{3}{*}{$\begin{array}{r}\text { в плаз- } \\
\text { ме }\left(\mathrm{m}_{\mathrm{cp}}\right), \\
\text { мкг }\end{array}$} & \multicolumn{2}{|c|}{ в гемолизате } & \multirow{3}{*}{$\begin{array}{c}\text { в } \\
\text { плазме } \\
\left(\mathrm{m}_{\mathrm{cp}}\right), \\
\text { мкг }\end{array}$} & \multirow{2}{*}{\multicolumn{2}{|c|}{$\begin{array}{c}\text { с форменными } \\
\text { элементами } \\
\text { крови } \\
\end{array}$}} \\
\hline & & & & & \multirow{2}{*}{$\left(\mathrm{m}_{\mathrm{cp}}\right), \mathrm{MKI}$} & \multirow{2}{*}{$\begin{array}{c}\% \\
\text { (от вво- } \\
\text { димой } \\
\text { дозы) }\end{array}$} & & & \\
\hline & & & & & & & & m, мкг & $\begin{array}{c}\% \text { (от } \\
\text { вводимої } \\
\text { дозы) }\end{array}$ \\
\hline 5.1 & VCR & 1000 & 74 & \multirow{2}{*}{660.65} & 647.26 & 64.73 & \multirow{2}{*}{339.35} & 30 & 30.79 \\
\hline 10 & VCR & 1000 & 358.58 & & 641.42 & 64.14 & & 30 & 30.21 \\
\hline 5.1 & VBL & 500 & 215.49 & \multirow[b]{2}{*}{698.88} & 284.51 & 56.90 & \multirow{2}{*}{301.12} & 267.88 & 26.79 \\
\hline 10 & VBL & 1000 & 433.60 & & 566.40 & 56.64 & & 265.28 & 26.53 \\
\hline
\end{tabular}

Скорость элюента может влиять на разрешение хроматографического пика (рис. 2), оптимальной скоростью элюента является 8-12 cм $3 /$ ч для колонок длиной 10 см и 5.1 см. Количественное содержания VCR и VBL рассчитывалось ранее разработанным и валидированным методом (уравнения калибровочных графиков: $\mathrm{y}=0.0195 \mathrm{x}$ +0.0112 для VCR и y=0.0192+0.0115 для VBL, где х- оптическая плотность раствора

$\boldsymbol{X а л а х а к у н ~ и ~ д р . ~ / ~ С о р б ц и о н н ы е ~ и ~ х р о м а т о г р а ф и ч е с к и е ~ п р о ц е с с ы . ~ 2 0 1 8 . ~ Т . ~ 1 8 . ~ № ~} 2$ 
при 295 нм для VCR и при 268 нм для VBL). Фракция, в которой показатель оптической плотности превышал 1.0, для более достоверного расчета содержания препарата, разбавлялась водой дистиллированной до достижения диапазона оптических плотностей 0.1-1.0, который относится к пределу аналитической области методики.

Таблица 5. Количественное содержание найденного связанного ТИА в процентном отношении к общей связанной фракции препарата

\begin{tabular}{|c|c|c|c|c|c|c|c|c|}
\hline \multirow{3}{*}{$\begin{array}{c}\text { Длина } \\
\text { колон- } \\
\text { ки, } \\
\text { см }\end{array}$} & \multirow[b]{3}{*}{ ТИА } & \multicolumn{7}{|c|}{ Связанные фракции препарата } \\
\hline & & \multirow{2}{*}{$\begin{array}{c}\text { в гемоли- } \\
\text { зате } \\
\left(\mathrm{m}_{\mathrm{cp}}\right), \text { мкг }\end{array}$} & \multicolumn{3}{|c|}{ в плазме } & \multicolumn{3}{|c|}{$\begin{array}{c}\text { с форменными элементами кро- } \\
\text { ви }\end{array}$} \\
\hline & & & $\left(\mathrm{m}_{\mathrm{cp}}\right)$, мк & $\begin{array}{c}\% \text { (от } \\
\text { общ. свя- } \\
\text { занной } \\
\text { фракции) }\end{array}$ & Cp. \% & m, мкг & $\begin{array}{c}\text { \% (от общ. } \\
\text { связанной } \\
\text { фракции) }\end{array}$ & Cp. \% \\
\hline 5.1 & VCR & 647.26 & 339.35 & 52.43 & \multirow{2}{*}{52.67} & 307.91 & 47.57 & \multirow{2}{*}{47.33} \\
\hline 10 & VCR & 641.42 & 339.35 & 52.91 & & 302.07 & 47.09 & \\
\hline 5.1 & VBL & 284.51 & 301.12 & 52.92 & \multirow{2}{*}{53.04} & 267.90 & 47.08 & \multirow{2}{*}{46.96} \\
\hline 10 & VBL & 566.40 & 301.12 & 53.16 & & 265.28 & 46.84 & \\
\hline
\end{tabular}

Таблица 6. Количественное содержание найденных и связанных ТИА с форменными элементами крови

\begin{tabular}{|c|c|c|c|c|c|c|c|c|}
\hline \multirow{2}{*}{$\begin{array}{l}\text { № ко- } \\
\text { лонки }\end{array}$} & \multirow{2}{*}{ ТИА } & \multirow{2}{*}{$\begin{array}{c}\text { Введено в } \\
\text { образец, мкг }\end{array}$} & \multicolumn{3}{|c|}{ Найдено } & \multicolumn{3}{|c|}{ Связанно } \\
\hline & & & m, мкг & $\mathrm{R}, \%$ & $\mathrm{R}_{\mathrm{cp},} \%$ * & m, мкг & $\mathrm{R}, \%$ & $\mathrm{R}_{\mathrm{cp}}, \% *$ \\
\hline I & \multirow{4}{*}{ VCR } & 1000 & 531.51 & 53.15 & \multirow{4}{*}{53.09} & 468.49 & 46.85 & \multirow{4}{*}{46.91} \\
\hline II & & 1000 & 531.27 & 53.13 & & 468.73 & 46.87 & \\
\hline III & & 1000 & 530.66 & 53.07 & & 469.34 & 46.93 & \\
\hline IV & & 1000 & 529.99 & 53.00 & & 470.00 & 47.00 & \\
\hline I & \multirow{4}{*}{ VBL } & 1000 & 538.43 & 53.84 & \multirow{4}{*}{53.69} & 461.57 & 46.16 & \multirow{4}{*}{46.23} \\
\hline II & & 1000 & 538.11 & 53.81 & & 461.90 & 46.19 & \\
\hline III & & 1000 & 537.42 & 53.42 & & 462.58 & 46.26 & \\
\hline IV & & 1000 & 537.01 & 53.70 & & 463.00 & 46.30 & \\
\hline
\end{tabular}

*SD - VCR $( \pm 0.679)$, VBL $( \pm 0.645)$

В данной работе использовались сверхвысокие дозы препаратов 1000 мкг/мл, которые превышают в 1666 раз для VCR и в 1235 раз для VBL концентрации, обыч-

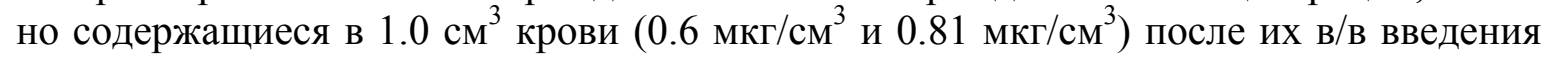
при химиотерапии. Обнаруженное содержание свободного VCR в гемолизате (таблица 2) для колонок I и II в среднем составило $35.86 \%$, а для колонок III и IV $35.27 \%$ от вводимой дозы. Содержание свободного VBL в гемолизате для колонок I и II в среднем составило $43.10 \%$, а для колонок III и IV $-43.36 \%$ от вводимой дозы ТИА.

Данные в таблицах 4 и 5, показывают среднее значение связывания в гемолизате для VCR - 64.44\% и для VBL - 56.65\% по отношению к вводимой дозе. С компонентами плазмы крови связывается в среднем $33.94 \%$ VCR и $30.25 \%$ VBL по отношению к вводимой дозе. В таблице 5 показаны результаты определения связывания с компонентами плазмы VCR - 52.67\% и VBL- 53.04\%, а также с форменными элементами крови VCR - 47.33\% и VBL- 46.96\% по отношению к общей связанной фракции препаратов.

В проведенном анализе с модельными образцами «В», подтверждаются данные, которые были получены в проведённом эксперименте с моделями «А» и «Б». 
Результаты, представленные в таблице 5, показывают, что 46,91\% от введенной дозы VCR и $46.23 \%$ VBL взаимодействуют с форменными элементами крови (эритроцитами) и остаются не обнаруженными. Эти показатели приблизительно совпадают со значениями, полученными в моделях «А» и «Б».

Полученные экспериментальные данные близки к результатам эксперимента, выполненного Ричард А. Бендером с соавторами [4]. В проведённых фармакокинетических исследованиях с использованием ароматически связанного радиоактивного $\left[{ }^{3} \mathrm{H}\right]-\mathrm{VCR}$ показано, что после 20 мин в/в введения препарат в собранной фракции, состоящей из плазмы, красных, белых кровяных телец и тромбоцитов, связывается в среднем на 48.2, 48.5 и 3.3\% соответственно [4]. На основе полученных экспериментальных данных, можно сделать вывод о высокой способности изучаемых алкалоидов связываться с компонентами плазмы и форменными элементами крови.

\section{Заключение}

Таким образом, установлено, что ТИА препараты обладают высокой способностью связываться с компонентами плазмы и форменными элементами крови. С компонентами плазмы связывание осуществляется для VCR на $52.67 \%$, а для VBL $53.04 \%$ от общего связывающегося количества ТИА препаратов. В эксперименте установлено, что взаимодействие VCR с форменными элементами крови (эритроцитами) составляет $46.91 \%$, a VBL - 46.23\% от вводимой дозы. В соответствии с полученными экспериментальными данными, можно определить оптимальные условия для инкапсулирования ТИА препаратов в эритроцитах для создания КН и осуществления направленного транспорта данных лекарственных веществ в организме.

\section{Список литературы/References}

1. Nicole C., Farnaes L. The Vinca Alkaloids. Cancer Management in Man: Chemotherapy, Biological Therapy, Hyperthermia and Supporting Measures. Dordrecht: Springer Science, 2011, Ch. 2, pp. 25-37.

2. Determann H. Gel Chromatography Gel Filtration Gel Permeation Molecular Sieves, Berlin, Heidelberg: Springer Berlin Heidelberg, 1969, $204 \mathrm{p}$.

3. Gel Filtration Principles and Methods Eppendorf-Netheler-Hinz GmbH: Amersham Biosciences, 2002, 124 p. https://www.sigmaaldrich.com/content/dam/sig ma-aldrich/docs/Sigma-

Aldrich/General_Information/1/ge-gelfiltration.pdf

4. Bender R.A., Castle M.C., Margileth D.A., Oliverio V.T., Clin Pharmacol Ther., 1977, Vol. 22(4), pp.:430-438.

5. Cameronf B.F., Separation Science, 1971, Vol. 6, No 2, pp. 229-237.

6. Erickson H.P., Biological Procedures Online, 2009, Vol. 11, No 1, pp. 32-51.
7. Hagel L., Current Protocols in Molecular Biology, 2001, Unit Number: Unit 10.9. DOI: 10.1002/0471142727.mb1009s44.

8. Magdeldin S., Moser A., Affinity Chromatography, 2012, pp. 3-29. DOI: $10.5772 / 39087$.

9. Malcolm M.J., J Forensic Sci Soc., 1977, Vol. 17(1),pp. 57-62.

10.Tammar A.R. Evans R.W., Moreland B.H., Murphy G.M., Biochemical society transactions, 1982, Vol. 10 (2), P. 126. DOI: $10.1042 /$ bst0100126.

11.Ó'Fágáin C., Cummins P.M., O’Connor B.F., Protein Chromatography Methods and Protocols: Methods in Molecular Biology / eds. D. Walls, S.T. Loughran. Totowa, NJ: Humana Press, 2011, pp. 25-33.

12.Nikolayenko I.V., Galkin O.Yu., Grabchenko N.I., Spivak M.Ya., Ukrainica Bioorganica Acta, Vol. 2, 2005, pp. 3-11.

13. Stratton F., Smith D.S., Rawlinson V.I., Journal of Clinical Pathology, 1968, Vol. 21, No 6, pp. 708-714. 
Халахакун Мудиянселаге Амила Дживанта - аспирант фармацевтического факультета ФГБОУ ВО «Воронежский государственный университет», Воронеж

Тринеева Ольга Валерьевна - д. фарм.н., доцент кафедры фармацевтической химии и фармацевтической технологии фармацевтического факультета ВГУ, Воронеж

Сливкин Алексей Иванович - д. фарм.н., профессор, зав. кафедрой фармацевтической химии и фармацевтической технологии, декан фармацевтического факультета ВГУ, Воронеж
Halahakoon A. Jeewantha - Ph.D. student, Department of Pharmaceutical faculty, Voronezh State University, Voronezh, e-mail: amilajh1982@hotmail.com

Trineeva Olga Valeryevna - doctor of pharmaceutical sciences, associate professor of pharmaceutical chemistry and pharmaceutical technology of pharmaceutical faculty of VGU, Voronezh, email: trineevaov@mail.ru

Slivkin Alexey I. - doctor of pharmaceutical sciences, professor, manager. chair of pharmaceutical chemistry and pharmaceutical technology, dean of pharmaceutical faculty of VGU, Voronezh, e-mail: slivkin@pharmvsu.ru 